\title{
A RESPONSABILIDADE DO FRANQUEADOR PELOS DÉBITOS TRABALHISTAS DO FRANQUEADO ${ }^{1}$
}

THE FRANCHISOR'S LIABILITY FOR THE FRANCHISEE'S LABOR DEBTS MARKET

Pedro PELEGRINI ${ }^{2}$

ISSUE DOI: 10.21207/2675-0104.2018.781

\begin{abstract}
RESUMO
O âmago do presente estudo é aclarar a possibilidade de responsabilização do franqueador por débitos trabalhistas de seu franqueado. $\mathrm{O}$ instituto da franquia se faz cada vez mais presente na rotina dos brasileiros, devido a sua grande seguridade institucional, bem como a sua alta rentabilidade. Apesar de ser modelo de renome entre os moldes de negócios, o instituto da franchising carrega consigo algumas dúvidas. A eventualidade de existir compromisso do franqueador adimplir débitos trabalhistas do franqueado é uma dessas questões, pois se essa for deflagrada, o fascínio pelo retro citado instituto pode vir a diminuir. Serão levantadas ao longo deste exame, três probabilidades da referida responsabilização. Duas delas, envolvendo outras figuras jurídicas consolidadas e sua aplicação e enquadramento ao instituto da franquia, à saber, terceirização e grupo econômico; bem como uma probabilidade doutrinária e social, a situação de hipossuficiência do trabalhador mediante o seu empregador. Ao fim, buscar-se-á esmiuçar a incidência dos os institutos, respeitando o ordenamento jurídico e o egrégio entendimento, sem penalizar a efígie da franquia. Perscrutaremos demonstrar que no desenvolvimento perfeito da franchising, não há como haver a questionada responsabilização, isto é, na incidência exata do disposto ao contrato de franquia, a obrigação de arcar com eventuais débitos trabalhistas do franqueado, está completamente afastada do franqueador. Para que tal relação obrigacional ganhe subsistência, carece de mutação nos moldes da franquia, ou seja, deturpação no que fora previamente alinhavado.
\end{abstract}

Palavras-chave: Franquia. Responsabilidade. Relação Jurídica. Seguridade Jurisdicional.

\footnotetext{
${ }^{1} \mathrm{O}$ presente artigo sintetiza a monografia de conclusão da pesquisa, realizada para o Programa Interno de Bolsas de Iniciação Científica (PIBIC 2017-2018) da Faculdade de Direito de Franca (FDF), Franca/SP.

${ }^{2}$ Discente da Faculdade de Direito de Franca (FDF), Franca/SP. Bolsista do Programa Interno de Bolsas de Iniciação Científica (PIBIC 2017-2018).
} 


\begin{abstract}
This aim of this paper is to clarify the possibility of making the franchiser responsible for franchisee labor debts. The franchising institution is everyday more common in Brazil, not only because of its high institutional security, but also due to its great profitability. Although it is a great business model in the market, franchising institutions still have some questions to be answered. The possibility for the franchiser to adhere franchisee labor debts is one of these questions. If the franchiser is deflagrated, its admiration may decrease in the market. It will be analyzed in this paper three possibilities for the referred responsibility. Two of them involving other well based legal figures, known as outsource and economic group, along with the doctrinal or social probability, like the worker's financial insufficiency compared to the employee. In the end, it will be analyzed the incidence of the institutions respecting law order and the egregious understanding, without penalizing the franchising effigy. It will be tried to demonstrate that in the perfect franchising development there is no question about the doubted responsibility, it means that the exact incidence on the disposed franchising contract, the obligation to be charge with eventual franchisee labor debts is totally dismissed from the franchiser. In order that this obligational relation gains subsistence, it is needed a change on the franchising structure, it means, reconsidering misrepresentation of what was previously aligned.
\end{abstract}

Keywords: Family right. Shared Guard. Parental Alienation. Family Power.

$1 \quad$ INTRODUÇÃO

O presente estudo visa discorrer a respeito da figura jurídica e econômica da franquia, buscando elucidar questão conflituosa que reside no âmago do supracitado instituto. Entretanto, antes de adentrarmos os termos e conceitos técnicos, cumpre uma breve noção a respeito do instituto da franquia.

Pois bem, o conceito de franquia é disciplinado pelo artigo $2^{\circ}$, da lei $\mathrm{n}^{\circ} 8.955$, de 14 de dezembro de 1994:

\footnotetext{
${ }^{3}$ Art. $2^{\circ}$ : franquia é o sistema pelo qual um franqueador cede ao franqueado o direito de uso de marca ou patente, associado ao direito de distribuição exclusiva ou semi-exclusiva de produtos ou serviços e, eventualmente, também ao direito de uso de tecnologia de implantação e administração de negócio ou sistema operacional desenvolvidos ou detidos pelo franqueador, mediante remuneração direta ou indireta, sem que, no entanto, fique caracterizado vínculo empregatício.
}

Trazendo para uma definição em termos mais práticos e de mais fácil entendimento, Franquia é um método para distribuição de produtos e/ou serviços, consistente em uma parceria entre franqueadora (empresa mais experiente) e franqueado (empresa menos experiente), no qual a

\footnotetext{
${ }^{3}$ Disponível em: http://www.planalto.gov.br/cciviL_03/LEIS/L8955.htm. Lei das Franquias. Último acesso em $1^{\circ}$ de setembro de 2018.
} 
primeira transfere à última, no todo ou em partes, a competência por ela desenvolvida no respectivo ramo de atividade. Visto isso, traremos mais alguns conceitos que se fazem importantes para a compreensão do instituto da franquia.

Primeiro vamos "as partes", como explicitam as definições trazidas acima, elas são duas, o franqueador, que é a empresa que fornece a competência por ela desenvolvida mediante remuneração, e o franqueado, aquele que recebe e desenvolve tal competência e que remunera. Visto isso, passemos a remuneração, que nesse formato recebe o nome de royalties. Royalty é uma remuneração periódica paga pelo franqueado a seu franqueador pelo uso de sua competência, usualmente, trata-se de um percentual do faturamento bruto do franqueador.

Os personagens do contrato e a remuneração são os principais apontamentos sobre a franquia, mas não os únicos, cumpre ressaltar mais dois pontos, a taxa de franquia (ou taxa inicial) e a circular da oferta de franquia.

Cronologicamente, vem primeiro a circular da oferta de franquia, que é um documento entregue ao candidato pelo franqueador antes de qualquer outro ato, contendo informações claras a respeito de como funciona a rede de franqueados e a maneira como se dará a relação que estes irão estabelecer. Vem então o pagamento da taxa de franquia, que é quantia única, paga pelo franqueado ao franqueador para que este possa aderir ao sistema. Cumpre ressalva de que a circular da oferta de franquia vincula as partes, ou seja, uma vez apresentada, o contrato de franquia celebrado posteriormente deve seguir o que fora estipulado nela.

Portanto, na fase pré-contratual, temos a circular da oferta de franquia entregue pelo franqueador a seu candidato, quando este efetua $o$ pagamento da taxa inicial e assina o contrato, passam as partes a franqueador e franqueado, desenvolvendo sua relação, um entregando competência e o outro pagando royalties.

Visto isso, caracterizado de maneira necessária o conceito de franquia, o presente trabalho busca estudar a possibilidade de descaracterização de tal instituto, responsabilizando o franqueador pelos débitos trabalhistas do franqueado. Ou seja, discorre sobre a possibilidade de uma exceção à regra geral, pois como visto acima, franqueador e franqueado são pessoas jurídicas de existência distinta, sendo cada uma responsável pelos seus débitos trabalhistas.

No primeiro capítulo deste estudo vislumbraremos o chamado grupo econômico, que encontra previsão legal no artigo $2^{\circ}$ da CLT, 
caracterizado por uma ingerência do franqueador na esfera administrativa e financeira do franqueado, logo, se este faz parte do corpo que comanda a empresa deve fazer parte daqueles que se responsabilizam por sua inadimplência.

O segundo capítulo do estudo traz uma questão muito mais social e humana do que jurídica, a hipossuficiência do trabalhador perante seu empregador. Apesar de não existir previsão jurídica a respeito de tal questão é nítido que o empregado de uma franquia se encontra em clara situação de desvantagem perante seu empregador, de fato então seria mais justo que os franqueadores, percebendo a relação de inadimplência de seus franqueados para com seus empregados, sanassem tal problema. Por outro lado, tal situação destruiria um elemento essencial da franquia que é a distinção de pessoas jurídicas. Seria tal medida, sugerida por alguns poucos doutrinadores, a melhor maneira para sanar a manifesta desvantagem do funcionário em relação a seu empregador?

E por fim, a questão de maior incidência prática na realidade, a aproximação do instituto de franquia ao método da terceirização. A lei das terceirizações $n^{\circ} 13.429$ de 31 de março de 2017, regulamenta o instituto e prevê que no caso de inadimplemento dos compromissos do contratado para com seus terceirizados, deve o contratante adimpli-los com direito de regressão ao contratado. Foi motivo de questionamento em tribunais se tal possibilidade deveria se estender ao instituto das franquias, vistas as semelhanças entre as duas figuras jurídicas. Ainda no presente capítulo será também objeto de discussão, as alterações que a reforma trabalhista, agora em vigor, poderá trazer ao instituto da franquia.

Ante o exposto tecendo, nos capítulos de desenvolvimento, considerações e pesquisas a respeito de cada um dos pontos suscitados nesta introdução, buscaremos levar à franquia maior esclarecimento e, com certa ousadia, aperfeiçoamento. Visto que, um instituto com imensa relevância e incidência como este, não pode se ver exposto a questões que dizem respeito diretamente a sua caraterização ou não. Essas questões são de cunho elementar da franquia, logo, seu saneamento, implicará em ainda mais segurança e confiabilidade no modelo de negócio da Franquia. Mediatamente, estes sãos os objetivos centrais deste estudo. 
O chamado "Grupo Econômico", encontra-se disciplinado no $\operatorname{art.} 2^{\circ}$, par. $2^{\circ}$, da Consolidação das Leis do Trabalho:

\begin{abstract}
Art. $2^{\circ}$ : Considera-se empregador a empresa, individual ou coletiva, que, assumindo os riscos da atividade econômica, admite, assalaria e dirige a prestação pessoal de serviço. [...] Par. $2^{\circ}$ : sempre que uma ou mais empresas, tendo, embora, cada uma delas, personalidade jurídica própria, estiverem sob direção controle ou administração de outra, constituindo um grupo industrial, comercial ou de qualquer outra atividade econômica, serão, para efeitos da relação de emprego, solidariamente responsáveis à empresa principal e cada uma das subordinadas. ${ }^{4}$
\end{abstract}

Portanto, se extrai da legislação trabalhista, conceito do referido capítulo, quando uma ou mais empresas, embora tendo existência jurídica própria, estiverem sob direção ou administração de outra.

Feita a caracterização do que venha a ser o instituto de direito trabalhista, vamos ao grupo econômico e a sua possibilidade de concretização na franquia. Mesmo que por obrigação assumida contratualmente, o franqueador seja obrigado a dar assistência ao franqueado (aja visto que precisa também adimplir com sua prestação no contrato, a competência), cada um corre o próprio risco, em campos jurídicos e econômicos determinados. Portanto, tratam-se de partes autônomas, amarradas e limitadas por um contrato de prestações sinalagmáticas, vale de exemplo rápido: caso um franqueado passe por dificuldades financeiras em seu produto e venha a falência, de nada essa afeta aos demais franqueados, bem como ao franqueador; paradoxalmente, caso algum franqueado tenha mais sucesso que os demais em seus rendimentos, estes, em nada aproveitarão a ninguém.

Esclarecido então que, num contrato de franquia com aperfeiçoamento exato, franqueador e franqueado tem existências distintas a exceção é que nos interessa e é nela que reside o ponto de convergência entre os dois institutos apresentados até o momento. A lei de franquias, $\mathrm{n}^{\circ}$ $8955 / 94$ é clara em seu artigo $2^{\circ}$ ao dispor que a responsabilidade de franqueador e franqueado estão completamente separadas, contudo, ela apresenta uma condição para isso: "desde que não fique caracterizado vínculo empregatício."

Essa última citação é a incorporação da Consolidação das Leis do Trabalho à Lei das Franquias visando disciplinar, portanto, as anomalias

\footnotetext{
${ }^{4}$ Disponível em: http://www.planalto.gov.br/ccivil_03/Decreto-Lei/Del5452.htm. Consolidação das Leis do Trabalho. Último acesso $1^{\circ}$ de setembro de 2018.
} 
nos contratos de franchising em que a empresa franqueadora interfere diretamente na gestão da franqueada. E, então, quebra-se o limite de responsabilidade, passando a ambas as partes serem solidariamente responsáveis, visto que comungam da mesma administração.

Antes de prosseguir convém separar, por motivos didáticos, as possibilidades de interferência:

a) A direção e/ou administração das empresas pelos mesmos sócios e gerentes, além do controle de uma pela outra (tratase da ocorrência mais recorrente na configuração deste tipo de caso;

b) Mesma origem de capital e/ou patrimônio. Caso em que as fontes de receitas são as mesmas;

c) A comunhão ou conexão de negócios. Caso mais grave pois a franquia estaria privilegiando um de seus franqueados a ponto de partilhar dos negócios junto a ele;

d) Utilização da mão-de-obra comum de uma empresa em aproveitamento da outra. Casos em que uma das empresas é contratante, mas ambas se utilizam da mão-de-obra. É um caso praticamente explícito de quebra da responsabilidade trabalhista visto que um funcionário serve a dois patrões.

O rol apresentado fora elaborado baseado na incidência prática, ou seja, levando em conta os casos de maior frequência. No entanto, tal rol está longe de ser taxativo, haja visto que se faz impossível compilar todas as maneiras possíveis de ingerência. Posto isso, detectado e provado meio de ingerência, ou qualquer possibilidade deste, configura-se o grupo econômico, possibilitando então a não mais separação jurídica da existência de franqueador e franqueado, originando assim a existência de solidariedade entra eles, pelos débitos trabalhistas existentes.

Cumpre, em contraponto ao instituto apresentado, a posição da Ana Cristina Von Jess ${ }^{5}$, de que o ordenamento brasileiro é deficitário ao disciplinar os chamados grupos econômicos, pois existem muitos tipos de desdobramentos que podem acontecer advindos deste e a definição constante nos dois dispositivos legais apresentados é insuficiente para fazer esse enquadramento.

Ainda comungando da linha de raciocínio da vênea jurista, para que não exista deturpação problemática da figura do grupo econômico aplicado ao contrato de franquia, é necessário que cada 'pseudogrupo

\footnotetext{
${ }^{5}$ Disponível em: https://www.abf.com.br/numeros-do-franchising/. Números do setor/vonJess. Último acesso $1^{\circ}$ de setembro de 2018 .
} 
econômico", aqueles em que existe possibilidade de enquadramento, seja analisado de maneira concreta respeitando as peculiaridades e singularidades de cada tipo de contrato, bem como das partes que são protagonistas destes.

Exemplificando o apontamento feito pela mestra, de um contrato de franquia cumprido regiamente a letra da lei e analisado particularmente pelo judiciário, tem-se a análise de recurso de revista pela $2^{\mathrm{a}}$ Turma do Tribunal Superior de Trabalho:

RR-1.141/2001-012-10-00: “(...) É de se reconhecer que o vínculo estabelecido entre as empresas, mediante contrato de franquia, é regido, especificamente, pela lei supramencionada [Lei $\mathrm{n}^{\circ}$ 8955/94], (...) desde que não haja comprovação de realidade fática distinta, o que não restou configurado nos autos, conforme quadro delineado pelo eg. TRT. Recurso de Revista Desprovido."

Em contrapartida, houve um processo de certa repercussão por parte da mídia envolvendo Shell e E\&C combustiveis. O RR-3590005.2006.5.06.0014 - Fase Atual: E, em que a SDI-1 (subseção I Especializada em Dissídios Individuais), do Tribunal Superior do Trabalho manteve decisão que condenou a Shell Brasil Ltda., solidariamente, ao pagamento de débitos trabalhistas da E\&C Combustíveis Ltda., mesmo havendo contrato de franquia firmado entre as duas. Como ficou demonstrado que a E\&C era mera administrada da Shell, sem autonomia para desenvolver suas atividades, a SDI-1 manteve a descaracterização do contrato de franquia e concluiu pela existência de grupo econômico, com consequente responsabilização solidária por dívidas trabalhistas.

No resumo da RR constante acima ficam claro os elementos teóricos, apresentados nesse trabalho, presentes no vínculo existente, configurando então deturpação no contrato de franquia e posterior nascimento da solidariedade entre elas. Mais ainda, cumpre-se averiguar na referida decisão, a análise também da subjetividade do caso concreto, como pleiteado pela jurista supracitada.

Importa citar as duas ementas abaixo, que apesar de menos fama, possuem igual riqueza acadêmica para contribuir com o tema em estudo:

FRANCHISING. GRUPO ECONÔMICO. CARACTERIZAÇÃO PARA FINS DO ART. $2^{\circ}, \S 2^{\circ}$, DA CLT. RESPONSABILIDADE SOLIDÁRIA. A celebração de contrato de franquia não afasta a responsabilidade solidária quanto constatada a existência de grupo econômico. 
(TRT-1 - RO: 00019438720125010225 RJ, Relator: Jose Antonio Piton, Data de Julgamento: 02/07/2014, Segunda Turma, Data de Publicação: 17/07/2014)

a. FRANCHISING. GRUPO ECONÔMICO. CARACTERIZAÇÃO, PARA FINS DO ART. $2^{\circ}, \S 2^{\circ}$, DA CLT.

- "A hierarquia entre empresas, embora ainda exista em alguns campos da atividade capitalista, cede lugar a uma nova estrutura empresarial de cunho horizontal, sem a liderança e organização da empresa-mãe, mas exercendo, entre si, com a devida reciprocidade, controle e fiscalização, participando de um mesmo empreendimento." (Juiz Denilson Bandeira Coêlho,

(TRT-10 - RO: 478200500810009 DF 00478-2005-008-10-00-9, Relator: Desembargador André R. P. V. Damasceno, Data de Julgamento: 16/11/2005, $1^{\text {a }}$ Turma, Data de Publicação: 25/11/2005).

Por autos, cumpre concluir que o grupo econômico aplicado ao instituto da franquia trata-se de uma anomalia no referido instituto em que o franqueador fornece competência diferente do que o estipulado em contrato, ingerindo no negócio/gestão de seu franqueado, caracterizando a relação empregatícia, e assim, quebrando a regra da responsabilidade separada das existências jurídicas, fazendo com que o franqueador seja responsabilizado por eventuais débitos trabalhista de seu franqueado.

\section{HIPOSSUFICIÊNCIA DO TRABALHADOR}

O presente capítulo do estudo visa analisar o instituto da franquia sob o prisma do trabalhador como pessoa levando em conta as suas individualidades e precariedades. Buscaremos uma análise mais humana e social do que propriamente legal. Portanto, o abordado no presente capítulo discorrerá de maneira mais hipotética do que realista, buscando base mais principiológica do que regimental.

No trabalhador têm-se o lado geralmente mais fraco na relação de emprego, pois é certo que o empregador detém maior poder sob o empregado do que o empregado sobre o empregador. Buscamos, portanto, enxergar de maneira correta essa situação para dizer se tal desproporção, mesmo que atípica, seria ou não embasamento para uma possível responsabilização do franqueador pelos débitos de seu franqueado com seus funcionários.

Em noções superficiais buscar-se-á dizer se tal desconformidade entre patrão e funcionário, ainda que não suscitada em nenhum dispositivo 
legal do ordenamento jurídico pátrio, poderia ser sustentação para que, objetivando-se equilibrar essa balança, sobreviesse uma responsabilização.

De início, cumpre analisar algumas máximas e amostras do trabalhador no âmbito jurídico. A máxima principal que norteia o princípio da hipossuficiência do trabalhador é de que 'o trabalho não é mercadoria', portanto, não seria correto equiparar serviços prestados a produtos, fornecendo-lhes o mesmo tratamento. Outra célebre frase que norteia o princípio protecionista ao trabalhador, prelecionada pelo célebre Henry Ford 'o trabalhador é o elo mais fraco da economia e nenhuma corrente pode ser mais forte que seu elo mais fraco'.

Além disso o Relatório Justiça de 2016, informa que a Justiça do Trabalho apresenta disparadamente a maior taxa de conciliação do Poder Judiciário (25\%), quando se tem o trabalhador no polo ativo da relação jurídica. Assim sendo, em nenhum outro ramo do direito brasileiro se concilia tanto. Isso mostra que, até mesmo quando as partes da relação de trabalho chegam ao desgaste máximo, recorrendo ao judiciário, a posição de fraqueza do trabalhador sobrevém e mostra que é mais interessante dar cabo aquela pendência aceitando o que fora proposto pois a chance de ver sua pretensão jurisdicional atendida é mínima.

Cumpre também importar da prática empresarial, que, aos primeiros sinais de crise em uma empresa, os cortes mais drásticos e imediatos ocorrem nas esferas dos trabalhadores com demissões em massa, flexibilização dos direitos, precarização e informalidade. O trabalhador, mesmo que não tenha contribuído para o insucesso da empresa, é o primeiro a ver sua realidade ser modificada para sanar a crise financeira atravessada.

Por fim, não é errado colocar o trabalhador como meio de resultado no esqueleto de uma empresa, ou seja, na maioria das grandes corporações, a maioria dos funcionários não exerce função diretiva, sendo guiado pelas decisões tomadas por superiores e trabalhando para realizar o que fora pensado por terceiros. Que muitas vezes tomam essas decisões baseadas em decisões de superiores guardando, então, as diretrizes decisórias de uma empresa à poucas cabeças pensantes. Dessa forma, é quase certo que aquele que se verá com débitos trabalhistas inadimplidos contribuiu pouquíssimo para tal situação de inadimplemento, apenas fez o que lhe fora mandado fazer. Assim sendo, fica ainda mais explícita a hipossuficiência, visto que o trabalhador é vítima de um insucesso que, na maioria das vezes, não ajudou a dar causa. 
Entretanto, calha ressaltar que não existe implicação legal imediata entre hipossuficiência do trabalhador e a responsabilização do franqueador de seu franqueado para com aquele. Novamente, o que se pretende com esse capítulo do estudo, é mensurar se tal situação de desvantagem ensejaria um embasamento para que tal possibilidade fosse concedida, apesar de não existirem ainda precedentes legais para tal responsabilização.

Apresentados todos esses pontos, chegamos à pergunta centro do presente capítulo, caso o empregado de uma rede de franquias, ao ver seu crédito inadimplido pelo empregador, poderia requerê-lo perante ao franqueador?

Apesar de todos os elementos supracitados, e estando mais do que caracterizada a situação de grande desigualdade entre o empregador com seu empregado, tal possibilidade não existe, e não está próxima de existir no nosso ordenamento jurídico. Primeiro porque destruiria o instituto da franquia, visto que romperia completamente a separação de figuras jurídicas gerando, assim, uma unidade entre o franqueador com cada franqueado seu e se for para ser uno, estaríamos falando de filiais e não de franqueados.

Mas supondo por intuitos meramente acadêmicos, que se criasse apenas no âmbito da justiça trabalhista, no caso específico do trabalhador que não conseguiu ver seu débito atendido pelo seu empregador, a responsabilidade subsidiária do franqueador. Imaginem uma franquia como a Localiza, que conta com milhares de agências espalhadas pelo país, todas elas com dezenas de funcionários. Supondo que uma delas não obtenha sucesso e não cumpra seus débitos com os empregados, o encargo gerado para a franqueadora seria imensamente desproporcional. Mesmo que de maneira subsidiária, a empresa seria responsável por um número excessivo de funcionários.

Além do que, como o franqueador não pode ingerir na administração do negócio do franqueado, sob pena de configuração de grupo econômico, se a administração do franqueado não foi suficiente para o sucesso da empresa, não é justo que o franqueador responda por algo a que ele não deu causa.

Conclui-se, portanto, que apesar de ser manifestadamente hipossuficiente a relação entre o trabalhador e seu empregador, e, de tal relação merecer os mais cuidadosos atos da justiça, tal desproporção nada tem a ver com o instituto da franquia, é inerente a qualquer vínculo empregatício, devendo ser sanada de maneira mais ampla pela justiça, 
fortalecendo (e não flexibilizando) os institutos legais que proporcionam garantias ao trabalhador.

Deturpar e deteriorar um instituto jurídico-econômico consolidado no mundo todo há muito tempo para sanar uma ínfima parte de um problema a que este não deu causa seria um retrocesso sem tamanho, até por isso, apesar de uma minúscula parte doutrinária defender tal situação, não houve (e certamente não haverá), embasamento legal para tal possibilidade de responsabilização do franqueador por eventuais débitos trabalhistas de seus franqueados.

\section{4 \\ APROXIMAÇÃO DO INSTITUTO A TERCEIRIZAÇÃO}

O capítulo final desta pesquisa busca a comparação entre duas figuras jurídicas extremamente importantes e corriqueiras, a terceirização e a franquia. $\mathrm{O}$ instituto da franquia já fora conceituado ao longo deste estudo, portanto, cumpre fazer uma rápida caracterização da terceirização para melhor entendimento do que se objetiva neste capítulo. A priori, no entanto, cumpre salientar que a aproximação destes dois institutos, diferentemente do apresentado no capítulo anterior, já fora de considerável número de litígios judiciais, por isso figura em nosso trabalho.

Tem-se por definição consagrada ao longo dos tempos que terceirização significa a contratação de terceiros por parte de uma empresa, para realização de atividades gerais, não essenciais, visando à racionalização de custos, à economia de recursos e à desburocratização administrativa. Ou melhor, terceirizar era contratar alguém para praticar atividade subsidiária e complementar àquela que seria desenvolvida. De exemplo rápido e prático, os porteiros de uma instituição de ensino. Ao invés de se preocupar com a burocracias inerentes as funções de portaria, que não são objetos da atividade prestada pela escola, contrata-se empresa especializada no ramo para desempenhar a função. Terceiriza-se o serviço.

Contudo, já de plano, cumpre dizer que com o advento da Lei 13.467, de 13 de junho de 2017 (popularmente conhecida como reforma trabalhista), passa a existir também a possibilidade de uma empresa terceirizar não mais apenas as atividades chamadas 'meio", mas também as chamadas 'fim". Voltando ao nosso exemplo, antes da vigência do supracitado dispositivo legal, poderiam ser terceirizadas apenas as atividades complementares no caso em tela a portaria. Com a nova ordem, é possível terceirizar também a atividade finalística, ou seja, a instituição 
de ensino também poderá terceirizar seus professores, coordenadores e demais colaboradores que praticam diretamente o ensino.

Apesar de simplória e breve, essa contextualização de terceirização servirá para a comparação que se almeja. A súmula 331 do Tribunal Superior do Trabalho, que trata da terceirização, traz no seu item IV disposições a respeito, complementadas pelo item VI, do mesmo dispositivo:

\begin{abstract}
$\mathrm{V}$ : O inadimplemento das obrigações trabalhistas, por parte do empregador, implica a responsabilidade subsidiária do tomador dos serviços quanto àquelas obrigações, desde que haja participado da relação processual e conste também do título executivo judicial. VI: A responsabilidade subsidiária do tomador de serviços abrange todas as verbas decorrentes da condenação referentes ao período da prestação laboral. ${ }^{6} \mathrm{I}$
\end{abstract}

Ante o exposto, entende-se que para os casos em que for escolhido o modelo da terceirização, não tendo adimplido o empregador (empresa escolhida para realizar o serviço, empresa terceirizada), o tomador de serviços (aquele que optou pela terceirização será responsabilizado subsidiariamente pelos referidos débitos trabalhistas.

Pois bem, foi alvo de demandas judiciais a possibilidade da aproximação da terceirização à franchising, e feita tal aproximação, responsabilizar subsidiariamente o franqueador pelos débitos trabalhistas de seu franqueado. Isto é, caso o funcionário de um franqueado não veja seus débitos adimplidos depois de cobrar de seu empregador, poderia este fazê-lo subsidiariamente do franqueador, da mesma maneira que ocorre no concernente a terceirização.

Isto posto, tal enquadramento de um dispositivo noutro, apesar de ter sido suscitado por alguns advogados em causa trabalhistas, não é possível, e mais, colocaria em risco a existência do instituto jurídico de franquia. De plano, a franquia tem seu próprio dispositivo jurídico não sendo cabível aplicar outro dispositivo simplesmente por conveniência, visto que não há possibilidade de analogia. Ora, a analogia é utilizada, em alguns casos, como suprimento a omissão legal se o ordenamento jurídico discorre manifestadamente sobre franquia, não há omissão passível de supressão por analogia. Praticar tal ato seria dar tratamento igual a

\footnotetext{
${ }^{6}$ BRASIL. Tribunal Superior do Trabalho. Súmula $n^{\circ}$ 331. Contrato de prestação de serviço. Legalidade. 
institutos jurídicos completamente diferentes sem qualquer razão aparente, a não ser a conveniência de uma parte no caso concreto.

Legalmente falando, o artigo $2^{\circ}$ da lei $\mathrm{n}^{\circ} 8.955$ (Lei das Franquias), é taxativo ao dizer em sua parte final que não pode haver vínculo empregatício entre franqueador e franqueado. Ora, a relação de terceirização é celebrada por um contrato de trabalho, portanto, é uma relação de vínculo empregatício puro. Assim sendo, não faz qualquer sentido tratar de maneira igualitária contratos que se excluem em dispositivos legais distintos. É de contrariedade imensa querer aplicar os conceitos prolatados de um dispositivo que disciplina vínculos empregatícios, a um contrato que é disciplinado por dispositivo que manifestamente exclui a possibilidade de vínculos empregatícios.

Por último, mesmo que fique configurado o vínculo empregatício, ainda assim a aproximação à terceirização não seria o remédio a ser aplicado ao caso concreto. Vendo-se configurado tal vínculo, constituir-se-á o chamado grupo econômico, deturpação na figura de franquia, tratado no primeiro capítulo deste estudo, remédio a ser aplicado para a situação. Que por sua vez promoverá a responsabilização solidária e não subsidiária entre franqueador e franqueado.

Tal entendimento a respeito de terceirização e franquia é consolidado pela jurisprudência, ficando de exemplo às sínteses de decisões trazidas abaixo:

CONTRATO DE FRANQUIA. RESPONSABILIDADE SUBSIDIÁRIA. INAPLICABILIDADE DA SÚMULA 331, IV, DO TST. A jurisprudência se consolida no sentido de não enquadrar a hipótese de franquia, que se exaure porventura na transferência de marca, patente ou expertise, na regra que protege o trabalhador em casos de subcontratação de mão-de-obra. Por isso, não cabe a incidência da Súmula 331, IV, do TST, tendo em vista tratar-se de autêntico contrato civil, cuja relação direta se estabelece entre as empresas, franqueada e franqueadora, e, não, entre esta e o trabalhador, ressalvada, por óbvio, a hipótese de fraude. Recurso de revista conhecido e provido. (TST, RR 2581005620035020202 258100-56.2003.5.02.0202, Relator: Augusto César Leite de Carvalho, Julgamento: 06/06/2011, $6^{\text {a }}$ Turma).

RECURSO DE EMBARGOS INTERPOSTO NA VIGÊNCIA DA LEI N. ${ }^{\circ} 11.496 / 2007$. RESPONSABILIDADE SUBSIDIÁRIA. FRANQUIA. SÚMULA N. ${ }^{\circ} 331$, IV, DO TST. O contrato de franquia não se confunde com o fenômeno da terceirização de serviços, visto que o franqueador não se beneficia dos serviços prestados pelos empregados da empresa franqueada. De fato, o contrato de franquia, que se encontra regido pelas normas de direito 
civil, apenas objetiva transferir a terceiros conhecimentos técnicos e administrativos para fins de abertura de empreendimento comercial. Desta feita, não há como imputar ao franqueado, na forma da Súmula n. ${ }^{\circ} 331$, IV, do TST, a responsabilidade subsidiária pelos débitos trabalhistas decorrentes da relação de emprego firmada entre o Reclamante e o franqueado. Precedentes da Corte. Recurso de Embargos conhecido e provido. (TST, E-RR 77 77/2005-001-02-00.8, Relator: Maria de Assis Calsing, Julgamento: 19/11/2009, Subseção I Especializada em Dissídios Individuais).

CONTRATO DE FRANQUIA. O contrato de franquia típico não enseja responsabilidade solidária ou subsidiária do franqueador, a teor do art. da Lei 8.955/94, que dispõe sobre o contrato de franchising. O contrato de franquia celebrado entre franqueado e franqueador distancia-se completamente da hipótese de terceirização e de grupo econômico, não ensejando responsabilização subsidiária ou solidária, a não ser no caso de haver desvirtuamento do contrato. Não restando provado nos autos tal desvirtuamento, não há como ser a reclamada franqueadora responsabilizada pelos direitos de natureza trabalhista dos empregados da franqueada. (TRT 16a região, 1834200801616006 MA 01834-2008-016-16-00-6, Relator: AMÉRICO BEDÊ FREIRE, Data de Julgamento: 17/01/2012).

Como já explicado nos apontamentos anteriores deste capítulo, é possível com o advento da Lei $\mathrm{n}^{\circ} 13.467$ que se terceirizem serviços fim, podendo, portanto, o franqueado escolher uma equipe e terceirizar o serviço que irá prestar. De exemplo, "A" é franqueada da rede de hotéis "B". "A" decide, baseada no advento da reforma trabalhista terceirizar todo o seu quadro de funcionários fins como camareiras, recepcionistas, cozinheiros e seguranças com a tomadora de serviços " $\mathrm{C}$ ". Tal terceirização é possível desde que a empresa escolhida para ser a tomadora de serviços, "C" no caso, submeta seus funcionários às competências prolatadas pela rede de hotéis " $\mathrm{B}$ ", atendendo ao contrato de franquia previamente estipulado.

Ainda não existem decisões a respeito do caso de haver inadimplência da tomadora para com seus funcionários. Contudo, a posição doutrinária e que certamente será a jurisprudencial é de que, a unidade franqueadora ("A" no exemplo citado no parágrafo anterior) responde subsidiariamente a tomadora de serviços ("C $\mathrm{C}$ " no caso), baseado na súmula 331 do TST. E, o franqueador (rede de hotéis "B”) não poderá ser responsabilizado pelos débitos destes funcionários, haja visto que com ele não celebrou obrigação empregatícia com nenhum dos sujeitos, nos moldes do artigo $2^{\circ}$ da Lei $\mathrm{n}^{\circ} 8.955$. 


\section{CONSIDERAÇÕES FINAIS}

Por fim, esmiuçadas separadamente as três possibilidades de responsabilização, cumpre concluir que, se a relação de franquia estiver perfeitamente configurada, com o franqueador fornecendo seu ' $k$ nowhow' e dando todo suporte que se comprometeu ao franqueado e este, por sua vez, se amoldando perfeitamente ao padrão que lhe fora repassado e repassando devidamente os royalties assumidos em contrato, não há no ordenamento jurídico brasileiro a possibilidade de responsabilização do franqueador pelos débitos trabalhistas do franqueado.

Assim, com a perfeita vinculação entre as condutas estipuladas em contrato e aquelas praticadas durante a existência da franquia, os débitos trabalhistas de franqueador e franqueado seguirão por realidades distintas, não podendo, sob a letra dos dispositivos legais em vigor, existir atrelamento do inadimplemento de um ao patrimônio do outro.

Repetidamente, para que exista possibilidade de responsabilização é necessário que sobrevenha anomalia no previamente acordado. Ou seja, que a conduta das partes seja diversa daquela que haviam estipulado no contrato de franquia.

Não há o que se falar em achegamento do instituto jurídico da terceirização ao da franquia, haja visto que ambos possuem seus dispositivos jurídicos, a terceirização pela lei das terceirizações $n^{\circ} 13.429$, bem como pela Súmula 331 do TST, e, a franquia por conta da Lei 8.955. Guardando ainda que tais figuras jurídicas beiram o antagonismo, visto que na relação entre franqueador e franqueado não pode haver vínculo empregatício e a terceirização é quase que puramente baseada em um vínculo empregatício.

Ainda no referido tema, pelo pouco tempo de vigor da Lei 13.647 ("'reforma trabalhista'), não houveram decisões a respeito da possibilidade de um franqueador terceirizar suas atividades. Contudo, pela analogia, e pela letra dos dois dispositivos citados no parágrafo anterior, o franqueado responde subsidiariamente ao tomador, por eventuais dissídios trabalhistas, ficando o franqueador inalcançável, visto que não celebrou contratos com o tomador de serviços e não responde por débitos do franqueado.

À vista disso, no tocante a aproximação dos modelos de negócio da franquia e da terceirização, fica excluída qualquer possibilidade desse avizinhamento ser base para responsabilização do franqueador pelos débitos trabalhistas de seu franqueado. 
Infelizmente, a posição de fraqueza e desproteção do trabalhador perante ao seu empregador, não pode ser corrigida destruindo o instituto jurídico da franquia. A hipossuficiência em que um empregado se encontra em relação a uma grande rede, não pode deturpar a letra do artigo $2^{\circ}$ da Lei 8.955 , a não ser que haja mutação na figura da franquia. A inferioridade do empregado, embora carente de atenção por partes dos provedores e praticantes do direito, não pode ser usada como pretexto para responsabilizar o franqueador pelos débitos trabalhistas do franqueado, visto que tal responsabilização, baseada por esse motivo, geraria um problema maior do que o que ela estaria sanando.

Nada obstante, caso exista uma deterioração da figura da franquia, momento em que o franqueador ingere na esfera administrativa, participando de decisões financeiras, ou até mesmo ele próprio orientando o curso que deve seguir a empresa franqueada, ficará caracterizado o grupo econômico. Logo, se o franqueador contribuiu para a falta de sucesso da empresa, originando pendências trabalhistas, é justo que ele responda solidariamente ao franqueado por estas.

Consubstanciando, funcionando regularmente a relação de franchising, dentro do contrato previamente amoldado, não há possibilidade legal no ordenamento jurídico de responsabilizar o franqueador pelos débitos trabalhistas do franqueado. Por outro lado, distorcida a relação estabelecida, e o franqueador passe a ingerir nos negócios de seus franqueados, configura-se o chamado grupo econômico, passando então, o franqueador, a responder solidariamente pelos possíveis débitos trabalhistas.

\section{REFERÊNCIAS BIBLIOGRÁFICAS}

ASSOCIAÇÃO BRASILEIRA DE FRANQUIAS. Números do setor. Disponível em:

https://www.abf.com.br/numeros-do-franchising/

BARROS. Alice Monteiro de. Curso de Direito do Trabalho. $6^{\circ}$ edição. São Paulo: LTr, 2010.

BARROSO, Luiz Felizardo. Franchsing e Direito. Rio de Janeiro: Lumen Juris, 2002.

BRASIL. Consolidação das Leis do Trabalho. Decreto-Lei n ${ }^{\circ}$ 5.452, de 1 de maio de 1943. Aprova a consolidação das leis do trabalho. 
BRASIL. Lei n ${ }^{\circ} 8.955$, de 15 de dezembro de 1994. Dispõe sobre o contrato de franquia empresarial (franchising) e dá outras providências. Disponível

em:http://www.planalto.gov.br/ccivil_03/leis/18955.htm. Acesso em: 23 abril 2018.

BRASIL. Lei $n^{\circ} 13.429$, de 21 de março de 2017. Altera dispositivos da Lei $n^{\circ} 6.019$, de 3 de janeiro de 1974, que dispõe sobre o trabalho temporário nas empresas urbanas e dá outras providências; e dispõe sobre as relações de trabalho na empresa de prestação de serviços a terceiros. Disponível em:http://www.planalto.gov.br/ccivil_03/_ato2015-2018/2017/lei/113429.htm. Acesso em: 23 abril 2018.

BRASIL. Lei n 13.467, de 13 de julho de 2017. Altera a Consolidação das Leis do Trabalho (CLT), aprovada pelo Decreto-Lei $\mathrm{n}^{\circ} 5.452$, de $1^{\circ}$ de maio de 1943, e as Leis $\mathrm{n}^{\circ} 6.019$, de 3 de janeiro de 1974, 8.036, de 11 de maio de 1990, e 8.212, de 24 de julho de 1991, a fim de adequar a legislação às novas relações de trabalho. Disponível em: http://www.planalto.gov.br/ccivil_03/_ato20152018/2017/lei/113467.htm. Acesso em: 23 abril 2018.

BRASIL. Tribunal Superior do Trabalho. Súmula n ${ }^{\circ} 331$. Contrato de prestação de serviço. Legalidade. Disponível em: http://www3.tst.jus.br/jurisprudencia/Sumulas_com_indice/Sumulas_Ind_301_350.html\#SUM-331. Acesso em 23 abril 2018.

CHERTO, Marcelo. Franchsing na Prática. São Paulo: McGraw-Hill, 2000.

JUSTIÇA EM NÚMEROS 2017. Conselho Nacional de Justiça (ano base 2016). CNJ. 2017.

MARTINS, Sérgio Pinto. Direito do Trabalho $27^{\circ}$ edição. São Paulo: Atlas, 2011.

PAMPLONA, Ricardo César. A padronização na formação dos contratos de franquia de serviços. $29^{\circ}$ edição. Joinville: Univille, 2005.

PRADO, Melitha Novoa. Franchsing na Alegria e na Tristeza. São Paulo: Do Autor: 2008. 